\title{
Violence against women of Belize in rural communities
}

\author{
Kiesha Warren-Gordon \\ Associate Professor \\ Criminal Justice and Criminology \\ Ball State University \\ UNITED STATES OF AMERICA \\ Contact author - Kiesha Warren-Gordon; kwarrengordo@,bsu.edu
}

\begin{abstract}
Belize is a diverse Central American country with a population of approximately 324,528, of which over $54 \%$ live in rural communities. The Belizean population is made up of Mestizo, Afro-Creole, Maya, Garifuna, and Mennonite identities, along with other groups such as East Indian, Lebanese, and Chinese, making the country rich with diverse cultures. Despite the vast cultural diversity of Belize, cultural constructions of femininity and masculinity have led to strong gender-based structures resulting in high rates of violence against women. According to the World Health Organization, $70.34 \%$ of Belizean women living in rural communities report experiencing episodes of intimate partner violence. In order to truly understand the phenomenon of violence against women, it must be conceptualized within the cultural context of Belize. In this paper, the author analyzes interviews with Belizean women from rural communities in central Belize who have been victims of violence at the hands of their intimate partners. Utilizing the theoretical perspective of intersectionality to explore how rurality shapes structural, political, and representational aspects of violence against Belizean women, this study will provide a robust understanding of Belizean women as victims of intimate partner violence. Policy implications are provided that would strengthen the social, cultural, and economic role of women in Belize. This research adds to the body of literature focusing on the victimization of women in rural communities.
\end{abstract}

Keywords: Belize, rural, intersectionality, interviews, abuse 


\section{Introduction}

Violence against women is a pervasive problem that exists in all cultures throughout the world. The extent of the problem varies, and how countries respond to it is often based on the ideological value placed on girls and women. In many countries, culture dictates that women and girls are seen as having less value to contribute to the cultural and economic development of a society, and, as a result, violence perpetrated against women and girls is placed in the context of "family problems" and not viewed as something to be addressed by state sanctions. Belize, like other countries, struggles to address this issue (Beske, 2009, 2014; McClaurin, 1996; McClusky, 2001). Examining the root cause of violence against women in Belize requires an examination of the structural and cultural norms that contribute to violence. While Belize as a country has worked to create laws that improve the quality of life for girls and women, the country's slow economic growth makes it difficult to reinforce laws in a broad sweeping manner due to a lack of resources (Beske, 2009, 2014).

In this paper, I utilize the theoretical perspective of intersectionality as developed by Kimberlé Crenshaw $(1989,1991)$ to understand the impact intimate partner violence has on Belizean women. Crenshaw's (1991) work around intersectionality recognizes that an individual's identity is not based on one facet, but by multiple identities and those identities often overlap in regard to race, gender, and class disparities. In this paper, I intentionally explore the intersectional nature of violence against women in Belize as it allows for the recognition of the multidimensionality of women in the context of Belizean culture, which is important from a decolonizing perspective (Mignolo \& Walsh, 2018).

Belize is a small, English-speaking Caribbean country, located on the northeastern coast of Central America and bordered by Mexico, Guatemala, and the Caribbean Sea. Known for its scenic terrain of rainforests and caves, as well as Mayan temples, the country is a favorite tourist destination. However, the Belizean people must contend with being a small developing nation with a poor infrastructure that relies heavily on tourism and agriculture as a major source of its economic base. The country is also home to the largest diversity of ethnic groups in Central America (Bonner, 2001; Premdas, 2003), consisting of Creole, Mestizo, Garifuna, Maya, Mennonite, Chinese, and East Indian people (Beske, 2009). The Creole people of Belize are mixed race, primarily of African and English descent, whose ancestry is traced to slavery originating from West Africa or the West Indies, and people from India who arrived as indentured servants. Mestizo people are one of the largest ethnic groups whose origins are traced back to Yucatán peoples, like the Maya. The Garifuna, who are African descendants of the slave trade, migrated from St. Vincent Island in the Caribbean in the mid-1800s, and the Mennonites arrived in the late 1950s during their quest to find a place to live autonomously. None of these groups (except the Maya) can claim to be original to Belize, but with each group bringing their own cultural norms of language, food, and spiritual beliefs, Belize is unique in that the richness of the ethnic diversity has not led to unrest. Belize does not share the same history of institutional segregation as the United States (U.S.) nor the ethnic turmoil of other Caribbean countries (McClaurin, 1996; Premdas, 2003), and this can be attributed to the ethnic boundaries as Belize is divided into six districts: Orange Walk, Corozal, Belize, Cayo, Stann Creek, and Toledo. Although diversity can be found within each district, each has a majority group that has historically dominated with its food, language, and other cultural influences. The country's push 
toward nationalism also contributes to the lack of ethnic and racial discord, as a sense of commonality among individuals developed around a national identity of being Belizean (Beske, 2009; McClaurin, 1996). The country is governed by a parliamentary democracy that consists of legislative, executive, and judicial branches that create, interpret, and enact the laws.

\section{Violence in the Belizean context}

Research regarding violence against women in Belize is sparse at best, and the focus on violence against women living in rural communities is even more limited, even though the vast majority of Belizeans live in rural communities. But although the research focusing on violence against women in Belize is limited, we know that it is a pervasive problem. As of 2018, Belize's total population was 324,528, with 54.28\% living in rural communities (Belize - Rural Population, n.d.). According to a Women's Commission report titled 2019: A Glimpse into Gender Issues in Belize, in 2018 there were 2,061 domestic violence calls to the police, and 78\% of those calls were from women. In 2018, there were 143 murders, and 124 were women (Women's Commission, n.d.). Belize, like other countries, has a widespread problem of violence against women that continues to manifest, although the government has enacted various laws to tackle the issue. In 1992, the Belize Domestic Violence Act was passed, and it was reenacted in 2007, extending protection orders for up to three years, broadening the category of people who can apply for an order of protection, and including options to add the requirement of child support. The reenacted law included the requirement that the police confiscate any weapon used in a domestic violence incident and required more severe penalties for violating protective orders. Along with working to make changes to the laws, the Women's Commission has been instrumental in working to change how people understand violence against women, and, as a result, they changed the definition of domestic violence to include financial abuse (Canada: Immigration and Refugee Board of Canada, 2012). The National Gender-Based Violence Plan of Action 2010-13 of Belize (2010), defines violence against women as "violence that is directed against a woman because she is a woman or that affects women disproportionately. It is any act of conduct based on gender, which causes death or physical, sexual or psychological harm or suffering to women, whether in the public or private sphere, including physical, sexual or psychological violence" (Lewis, 2010, p. 4).

Changes continued in 2010 when a domestic violence protocol for police officers was developed by the Women's Commission with the goal of improving the effectiveness of police investigative practices in addressing violence against women. The new protocol included sections such as guiding principles, police response procedures, court orders and directives on their enforcement, risk assessment, and procedures to submit complaints concerning inadequate police response (Canada: Immigration and Refugee Board of Canada, 2012). Although the country is working to combat violence against women, it continues to be a major social issue in Belize, especially in rural communities (Canada: Immigration and Refugee Board of Canada, 2012).

Research on violence against women in Belize is often situated within the broader context of violence against women in the Caribbean or Latin American (e.g., Sagot, 2005), focusing on drawing connections between violence on an individual level and the broader Caribbean or Latin American communities. These studies focus on the types of violence and their occurrence rates 
(Bucheli \& Rossi, 2019; Maydeu-Olivares, 2016; Sagot, 2005; Stewart et al., 2015). In these studies, there is a lack of examination of the differences in victimization patterns that may exist between women living in rural and urban areas. This contributes to the lack of understanding of violence perpetuated against women in rural communities. The limited existing research that does exist puts women worldwide who live in rural communities at greater risk of victimization and makes them less likely to receive support services (DeKeseredy \& Schwartz, 2008; Maume et al., 2014).

The vast number of studies that focus entirely on violence against women in Belize take an anthropological approach (Beske, 2009, 2014; McClaurin, 1996; McClusky, 2001). Although these studies have provided some insight into understanding violence against women in Belize, there is still a lack of understanding of how this phenomenon occurs and how law enforcement and other governmental agencies respond from an intersectional perspective, especially in rural communities. Crenshaw's (1991) work focuses on the idea that Black women, having a marginalized position within the U.S., are often "othered" when conversations arise as to how to combat violence against women. Services that are created to support women may not account for the different nuances that dictate a Black woman's ability to exit an abusive relationship and seek services differently compared to White women. She argues that the experiences of Black women must be understood by examining them as being both Black and women, and that those experiences of being a Black woman can only be understood in terms of the interactions of both aspects of identity. Crenshaw (1991) identifies three ways in which intersectionality presents itself: structural, political, and representational. Structural intersectionality posits that women of color who live in communities of lower socioeconomic status have limited financial resources, preventing them from escaping abuse when compared to White women. She notes that support centers in marginalized communities are often underfunded and have limited resources to support victims, compared to those in White communities. Political intersectionality addresses existing laws and policies that do not recognize the disparities in Black women's experiences as victims of violence. Representational intersectionality, according to Crenshaw (1991), allows for the cultural analysis of women of color as both women and people of color as opposed to historically falling into one or the other category. For example, she argues for examining women of color who are victims of violence by centering their experience as women of color and not as White women. That is, women of color do not have the same experiences regarding societal responses to interpersonal violence as White women do, and, as a result, the experiences of White women are normalized, while the experiences of women of color are seen as "other" (Crenshaw, 1991; Potter, 2006). Crenshaw (1991) focused on the multidimensionality of Black women; however, she recognized that the term and its applications can be used to examine the multidimensionality of any marginalized person or group of people.

Utilizing an intersectional framework for understanding the complexity of women living in rural communities in Belize who are victims of intimate partner violence requires a conceptualization of rurality. "Rural" must be understood as going beyond the idea of a geographic location that is often depicted as "country," or of agriculturally rich environments that are devoid of diversity (whether geographical or cultural) - i.e., as being typically populated by those of European ancestry (Hogg \& Carrington, 2003; Sandberg, 2013). Neglecting to acknowledge that other "rurals" exist contributes to the othering of groups that have traditionally been marginalized within society and historically have been invisible in the scholarship of rural 
criminology (Hogg \& Carrington, 2003; Pruitt, 2008; Sandberg, 2013). As Sandberg (2013) states, "There is a need for more location-specific, nuanced discussion on ruralities" (p. 353). Those who want to examine intimate partner violence in the context of rural Belize must take into consideration the more specific aspects of Belizean rurality. These include considering rural Belize as a series of remote geographical areas made up of rainforest and farming villages; the limited resources for health care, legal support, and the limited access to a phone, internet, or other communication devices; as well as the lack of transportation options that affect a Belizean woman's ability to leave an abusive relationship (DeKeseredy et al., 2012). The examination of intimate partner violence within rurality is a form of intersectionality, though often not recognized as such because the term intersectionality is not used in the analysis. This form of study is referred to as "implicit intersectional analysis" (Lykke, 2010, p. 76). Sandberg (2013) suggests that the study of the intersection of rurality and gender at times may also include other analytical categories in the study of intimate partner violence as a form of intersectionality. Recognizing the intersectionality of rurality allows for an analysis of groups of people who have been othered within the field of rural criminology (Sandberg, 2013). This study contributes to this field of work by moving Belizean women living in rural communities from marginalization to centering their lived experiences as victims of intimate partner violence.

\section{Methodology}

As a woman who self-identifies as Black and American, it was important that I recognize my privilege in working with women in Belize and the outsider position that I operate from as I attempt to understand violence against women in Belize. Asking women to share their most personal stories about the scariest times of their lives is something that I did not take lightly. It was important to me that I prepare myself as much as possible in regard to cultural competencies prior to conducting interviews. This was done by having meetings with the directors of the two centers where the interviews would take place prior to the interviews, as well as meeting with government, educational, and NGO officials to gain an understanding of how they perceive the problem of violence against women in Belize. I also spent time just "being" in Belize, walking the streets, talking to people, and visiting historic sites. My goal is that my work will contribute to the development of knowledge relevant to the current discourse regarding gender issues in Belize. Ensuring that the participants' voices are not misrepresented and that they are not being appropriated helps establish that this research contributes to the Belizean knowledge base and, at the same time, safeguards the ethicality of the research (Lazarus, 2013).

Prior to arriving in Belize, the study protocol received Institutional Review Board (IRB) approval by my home institution. Conducting research outside of the U.S. and the nature of the research required that extra safeguards be put in place to ensure the integrity of the research and the protection of those who participated in the interviews. The IRB committee was concerned that having the directors of the two shelters ask the women to participate in the interviews would be perceived as a possible conflict of interest. Explaining to the committee that the directors of the programs would establish that the women who participated in the interviews were emotionally able to share stories of the most vulnerable points in their lives was a protocol put in place to limit the post-traumatic stress that can occur by the retelling of traumatic stories such as those of intimate partner violence (Allen \& Wozniak, 2010). A series of semi-structured interviews were also approved as part of the IRB review. 
This study is part of a larger research project that explores the lived experiences of Belizean women who have been victims of abuse by their intimate partners. Interviews took place during August 2019 and February 2020. Seven women who participated in the study were from rural communities, which makes up the sample for the paper. Six of the women interviewed had been victims of intimate partner violence and received support from one of the two support centers in San Ignacio, Belize. One woman was still living with her abusive partner but was also receiving support. The two centers provide different services. One provides emergency housing and support services for women who are victims of abuse, while the other provides skills training and supplemental food assistance for children and women. Prior to conducting interviews, I spent significant time with the directors of both programs discussing the services they provide, in an effort to gain an understanding of the intricacies of each program.

\section{Participants/Interviews}

All of the women had between four to ten children and were between 26 and 47 years of age. All of them indicated that the relationship with their abusive partner began in some fashion during their teenage years, and all of the women had been married and divorced from their partner (except for one who is currently married to and living with her abusive husband). All of the women were in heterosexual relationships. Although the women currently live in the secondlargest town in Belize, all of them reported leaving their rural communities with the hope of receiving support for getting out of their abusive relationships. Three of the women selfidentified as Garifuna and were from villages in the Stann Creek District, two women selfidentified as Creole and were from villages in the Orange Walk District, and the other two women self-identified as Creole from the Toledo District. I only specify the region of the village and not the name of the village, to provide an extra layer of anonymity. Each interview took 90120 minutes. It was important to me that I spent time with the women in having a meaningful conversation prior to the interview, so before the start of the semi-formal interview, I engaged with each woman in general conversation. We talked about things such as the weather, hairstyles, parenting, discussing parts of Belize that I had traveled to and parts of the U.S., as well as sharing pictures of our children. The point of these conversations was to connect with the women in ways that went beyond the interviews. All interviews were conducted at one of the two centers in rooms that provided privacy and would not allow for interruptions. All of the women were given IRB-approved consent forms presented in both English and Spanish. Although it was written on the form, it was verbally reiterated to the women that choosing to participate or not in the interviews was not related to their ability to receive support services from the center that referred them to me. Along with having consent forms that did not require signatures, I also gave the women the opportunity not to take the consent form with them, recognizing that since one woman was still living with her abuser it could place her in more danger and that, for the other women, having the form could cause embarrassment. A series of open-ended questions had been established for semi-structured interviews as part of the IRB protocol. The intent was to meet with the women, allow for the conversations to develop organically, and to only use the question protocol if needed. A portion of the questions from the larger study was used to determine the participants' self-perception of race/ethnicity, as well as how living in rural communities impacted their ability to receive support in coping with and leaving the abusive relationship. The questions were posed using broad, open-ended queries. 


\section{Data/Findings}

Each interview was audio-recorded and transcribed immediately after the interview. All interviews took place in English, and when the women would codeswitch into Spanish or Creole, clarification was requested. The transcriptions were read over by a Belizean who speaks English, Creole, and Spanish to ensure accuracy. Fearing causing unnecessary harm to the women in having to relive their stories, I did not ask them to review the transcripts. However, they were offered the opportunity to review the final draft of this paper for accuracy. The transcriptions were then screened for themes using Berg's (2004) outline for conducting qualitative content analysis, by first developing the analytic categories based on the literature review, research questions, and review of the transcripts. This was then followed by developing a systematic selection of data chunks, sorting the data chunks into categories, and seeking out patterns based on the various categories. Based on the analysis, four categories emerged: motherhood, gender roles, pressure to keep the abuse a secret, and lack of support.

\section{Motherhood}

All of the women interviewed had more than three children. They discussed seeing themselves as mothers as key in framing their identity. When asked the question, "Tell me about yourself," all the women but one mentioned being a mother in their response. For example, one woman stated, "I have ten kids. I love my kids, everything I do is for my kids," and another woman stated, "I am a mom and all my kids are grown." Motherhood was a determining factor for many of the choices the women made. All of the women had multiple children, and many spoke about protecting their children as the key reason for attempting to remove themselves and their children from the abuse. For example, one woman stated, "I knew I had to leave when I saw my son. He got mad at his sister, and the words he used, he was so angry, he was becoming his dad." The expression of needing to remove themselves for the betterment of their children was also manifested when one woman stated, "He got mad and hit me with a stick while I was holding the baby. I had to leave because he almost killed my baby." Another woman expressing the same sentiment stated:

When my daughter was eleven, she started telling me that we should leave. We had left our village, and if we left him would have nowhere to go. Then when she was fifteen, I found out from her friend that he was touching her. I asked my daughter about it, and she said he had been touching her since she was eleven. I knew I had to do something to protect her and the rest of my children. He had so many different girlfriends that I never thought he was touching my daughter. He would bring the girlfriends to the house in his car. He would blow the horn so I would look out the window he would then drive off with them. But when she told me, I knew I had to do something. I'm a good mother, I should have known, I was so stupid. Just stupid back then.

Two women who left their abusive spouses spoke about leaving their children with their spouses as an act of saving their children from living in an abusive household. One shared the following: 
I did not want my children to see him hitting me. It was not good for them; they cried a lot. I don't have a job, so I just left. I took a bag of clothes and left. He took the kids to his sister. She is good with them and I see them every day. I walk them to school and walk them to his sister's house after school. My house is only one room and I sleep on the floor at his sister's house; they have beds.

The intersection of motherhood and rurality was exhibited when women discussed the need to leave their rural communities to both support their children and exit the abusive household. For example, one woman stated:

When we were living in [village] I had nothing. It was just us [children and abuser]. My daughter would say, "Let's leave, we can go to Belize City, we can be safe there. We can get help there." I knew we couldn't go there, too much crime. We needed move. I could get a job and support my kids. My daughter was right, there was nothing in [village] to help us. I could not go to the police officer in the village, he would just tell everyone. I needed to find us help. I know I'm a good mother. [inaudible] we ended up here. My daughter is going to school and other boys are in school. They don't want to go back [to the rural community]. They want to be here with me.

\section{Gender roles}

Some women expressed a clear understanding that there was abuse occurring due to their attempt to, or not to, conform to expected traditional gender roles. This notion was confirmed by one woman who stated, "We lived together and I did everything and he would still get mad and hit me." Another woman stated, "He got mad at me and hit me because I told my daughter that she could go with my sister. He said you are not me you don't give permission and then he hit me in my face." One woman reported that her refusal to conform to her expected gender role led to the end of her abuse. She shared the following:

I knew if I stopped cooking and cleaning he would leave. So I would feed my children before he came and told him there was no food. He would look but could not find the food. He would get mad and hit me, but then he would leave and finally he just did not come back. Then one day I came home and all his stuff was gone.

That the expectation was for women to follow traditional gender roles, and that when they did not meet those expectations they would be abused by their partner, which was a theme expressed by most of the women. All of the women described experiences of abuse occurring when a gendered role was not met. For example, a woman shared this occurrence before she married her husband:

We started dating in high school and he would me walk home. One day I walked home with my friends. Before I got to my street he was in the alley. I went over to talk to him and he grabbed me by the throat. He was mad because I did not wait for him. I knew I was supposed to wait and that he would be mad, I just didn't think he would hit me. 
Gender roles for women living in Belizean rural communities are aggravated by having to manage them with few resources. As articulated by one woman,

He won't give me money for food and there was no one I could ask. What was I supposed to do? When he gave money it wasn't enough. Living out there it was hard to get what we needed and he would get mad, hit me, and run off with his girlfriend.

\section{Keeping the abuse a secret}

All of the women spoke about people being aware that they were being abused, but not talking about the abuse. These occurrences were described as family and friends witnessing the abuse, or the aftermath of the abuse, but not offering any form of support or acknowledgment. Many of the women discussed the family not getting involved for various reasons. For example, a woman shared:

When we moved it was like nothing changed. My family knew what he did to me and never said anything. It was the same when we moved here. They didn't ask so I didn't tell. Once he beat me and I lost consciousness and he threw me in the ravine. Some stranger jumped in and saved me. He went to prison and I was able to get a divorce and my family still won't talk about the abuse. He will leave here and drive to my mom's house if he thinks the kids are there. It's okay because my husband is in Texas and we will be going there soon.

Another woman shared a similar sentiment:

Once we were married, we did not go around my family. My family never asked about me. Always had beautiful teeth and he beat me so bad that he knocked out my front tooth. When we went to see my family, my mom didn't ask about my beautiful teeth. She just looked at me. She knew he did it.

Intersectional aspects of this theme are reflected by the women who discussed feeling that they did not speak about the abuse not only because of the cultural expectations not to discuss such personal matters but also in fearing becoming part of the gossip and sensationalism in the rural or village community. The statement of "everyone knowing your business" was reiterated throughout my conversations with the women. The idea of other people knowing what was going on in one's life was a direct threat to perceived masculine norms in Belize and could lead to more violence against female victims. For example, one woman stated, "If people knew, he would get madder and the next it would be worse." This notion was also conveyed by another woman, who stated, "If he knew people were talking, it would make things worse. Everybody talks here, and if he finds out they are talking about us he will blame me, because you don't talk about things that make him look bad."

\section{Lack of support}

All of the women spoke about the lack of support in various forms in their rural communities. All of the women also spoke of either having no resources or the only resource 
being in the form of the police in their rural communities. One woman shared, "There are two police officers that we were supposed to see if we wanted to report abuse. They were never there; I went by once and they weren't there, so I just walked by and didn't go in." Another woman shared:

The police depot was too far from us and we only had one cell phone, so I never called. I would have to go to the police to get an order of protection but then you have to pay for it and my husband has the money.

Some women also spoke in terms of privacy violations if they involved the police in their rural community, making statements such as, "Everybody knows your business if the police come, everybody will know and it will be the talk."

For some women, the lack of support was from their families. Women expressed that although their families were aware, they did not offer to help them leave the abusive relationship. For example, a woman shared:

Before we moved, we were at our house and he hit me. My eye was swollen and we went to my mom's house. She asked me what happened. I said I fell. She didn't ask any questions; she just looked. She knew he hit me but didn't say anything. He didn't hit me again until after we moved.

Another woman shared, "He would push me and stuff, my brother knew but he never said anything to me about it. Once I left, he told me that he knew my husband was crazy." Some women expressed a lack of support coming from the criminal justice system. One woman expressed her frustration with the police by sharing the following:

When we were home in [a small village in southern Belize], there were two police officers and I never went to them because everybody knew that they wouldn't do nothing. One of them beats his own wife. So when we came here [San Ignacio] I thought it would be different. One day he was hitting me and the neighbor called the police. When the police came they took us both to jail. The police officer said I needed to learn a lesson. I will never call the police again for nothing.

Another woman expressed a very similar sentiment:

Once we moved, I would call the police and tell them that there was a woman and children locked in a house and screaming for help. The police never came no matter how many times I called. My husband would leave for work and lock us in the house. We couldn't leave. I even called a support hotline number, and no one ever came. No one cared. My neighbor would hear me screaming and she would see me, we would look at each other. She couldn't help because she was being abused too. One time she brought food over and put it through the window so me and the kids could eat.

Although the women did not speak about the lack of support from medical personnel, when asked only one of the women ever sought medical support while living in either rural 
communities or San Ignacio. Some of the women, however, shared with me the physical scars left from their abuse. When asked about why they did not receive medical help, they either indicated that their partner would not allow it, that they could not afford to see a doctor, or that the doctor was too far away. For example, one woman stated, "The clinic was closed and did not open until the next day. He would not let me go even the next morning. I just had to wrap it up and make do. It was too far to try to go anywhere else."

\section{Discussion}

Exploring violence against women in Belize through the lens of intersectionality allowed for an understanding of the complexity of identity of Belizean women. All of the women I interviewed were mothers, and motherhood shaped the need to exit their abusive relationships. Further, the intersectional relationship between motherhood and being a woman who is abused was represented in this study. As mentioned previously, all of the women interviewed have multiple children and spoke of concern for the children's physical and mental well-being. Motherhood within the Belizean context is part of gender identity, and having multiple children is expected due to the negative cultural framing of contraception, its limited availability, and abortion being illegal. Having multiple children and starting families during the teenage years are parts of the rural culture of Belize and the identity of the women (Beske, 2016; McClaurin, 1996; McClusky, 2001). Since these women are expected to begin to form families once they enter into a cohabiting relationship, and since motherhood is central to being a woman in Belizean culture (Beske, 2016; McClaurin, 1996; McClusky, 2001), allowing motherhood then to dictate their exiting of the abusive relationship is not surprising of Belizean women, given that they are usually the primary caregivers of children (Beske, 2016). All of the women I spoke to were unwavering in their want to be perceived as good mothers.

Gender roles also represent an intersectional aspect of violence against women in Belize. The expectation that women conform to traditional gender roles was represented in the themes of this study. All of the women recounted a lived experience of not conforming to the expected gendered behavior, resulting in disparate outcomes. For one woman, it resulted in her abusive husband leaving the household. As she recounted her conscious decision not to conform to her partner's expectations, she also recognized that his leaving would result in financial burdens she was not equipped to manage. For the other women, it resulted in physical abuse. The cultural expectation that women perform certain domestic acts within the home and conform to other gendered expectations is very much the norm for Belizean women (Gentry, 2007).

The lack of support was a clear theme in this study. The women spoke about a lack of support from family and friends, as well as government structures. Many of the women shared experiences of their family's awareness of the abuse but failing to acknowledge its impact on the victim. This can be attributed to the machismo aspect of the Belizean culture (Beske, 2016) - the notion of the man being the head of the household and that what the man says goes. As Belize is a patriarchal society, the idea of machismo is carried over into the extended family and the community, as no one questions the male's behavior regarding his family. The idea that what goes on in someone's house is not for anyone else to speak of was affirmed throughout my conversations, both formally and informally, with people I engaged with in Belize. With regard to the lack of support from the police and judicial system, all of the women spoke in negative 
terms about their interactions or lack thereof with the police. Although Belize has worked to train some of their police officers on how to deal with intimate partner violence, there is still work that needs to be done. Not all police receive the special training, and for women who live in rural villages, there is limited access to the police, with very few of those officers having the special training. During the course of conducting the research for this project, I inquired about officers in the rural villages receiving the training, and I was told that it was a "goal"; however, when and if it would occur was unclear. In many of the villages, there are as few as one to three police officers who work in the community. The limited number of officers makes it difficult to leave the rural community to go to Belmopan for training. Also, if intimate partner violence in the village communities is not reported, then it is less likely to be perceived as a problem requiring the need for the officers to receive the special training.

Belize only has two centers that support female victims of intimate partner violence. One is located in the town of San Igancio, and the other is located in Belize City. In this study, the findings provide insight into the lack of support given to female victims of violence in rural communities. However, there is much more needed to fully understand the experiences of female victims of intimate partner violence living in rural communities in Belize. The women in this study had all moved away from their villages two to five years prior to the interviews. Because there are no outreach centers in the rural communities of Belize, building relationships with women who live in rural communities may be difficult at best. During my time in Belize, I was told repeatedly that it is "taboo to talk about such things," especially to an outsider. As suggested by Lazarus (2013), I worked with women who were trusted by those who participated in this study to gain access. Vouching for someone's character goes a long way in Belize. As one of the participants stated, "If you are good with [the director of the program], then you are good with me." Future studies should focus on women who are currently living in rural communities, as their lived experiences will offer more of an in-depth understanding of the needs of women who cannot relocate to Belize City or San Igancio to access the support required to navigate exiting an abusive relationship.

These findings provide insight into the lack of support provided to female victims of violence in rural communities. The present study offers a robust exploratory understanding of violence against women in Belize; however, it is not without its limitations as the sample size of seven women is a major limitation. Although this study provides an in-depth understanding of women who left rural communities to seek support in exiting their abusive relationships, problems around issues of reliability, validity, and generalizability may present as problematic to some due to the sample size and the qualitative focus of the study. Each woman who participated in this study shared intimate personal details of her life and, as a result, the end goal should not be to replicate the experience for generalization purposes, but to continue to explore the topic in ways that allow for each woman to have a voice to articulate her experience.

\section{Conclusion}

Violence against women in rural Belize is a significant problem that affects every aspect of broader Belizean life. Victimization impedes a woman's ability to be a parental caretaker, a contributing member of society as a wage earner, and an overall productive member of society. Recognizing the intersectional positions in which Belizean women exist will allow stakeholders 
to begin to address the problem from a holistic approach. Developing strategies that support women as mothers and victims of abuse will help to empower them. In addition, working with women to combat the notion that spousal abuse is a private matter will provide an opportunity to change the national narrative around violence against women and girls. The findings in this study provide an opportunity for Belizeans to continue to engage in dialogue and, thus, to continue to develop ways to combat the issue.

\section{References}

Allen, K. N., \& Wozniak, D. F. (2010). The language of healing: Women's voices in healing and recovering from domestic violence. Social Work in Mental Health, 9(1), 37-55. https://doi.org/10.1080/15332985.2010.494540

Belize - Rural population (\% of total population). (n.d.). Retrieved February 29, 2020, from https://www.indexmundi.com/facts/belize/indicator/SP.RUR.TOTL.ZS

Berg, B. L. (2004). Qualitative research methods for the social sciences. (5th ed.). Pearson.

Beske, M. A. (2009). Applying international human rights laws to promote wellness within the community: On diminishing intimate partner violence in the context of western Belize. Global Public Health, 4(5), 490-499. https://doi.org/10.1080/17441690902815447

Beske, M. A. (2014). An analysis of the collaborative endeavors to lessen gender-based intimate partner violence in Cayo, Belize, and a case for anthropological engagement. Gendered Perspectives on International Development, Working Paper 304, 16-33. https://gencen.isp.msu.edu/files/8914/5201/1092/WP304.pdf

Beske, M. A. (2016). Intimate partner violence and advocate response redefining love in western Belize. Lexington Books.

Bonner, D. M. (2001). Garifuna children's language shame: Ethnic stereotypes, national affiliation, and transnational immigration as factors in language choice in southern Belize. Language in Society, 30(1), 81-96. https://doi.org/10.1017/s004740450100104x

Braun, V., \& Clarke, V. (2006). Using thematic analysis in psychology. Qualitative Research in Psychology, 3(2), 77-101. https://doi.org/10.1191/1478088706qp063oa

Bucheli, M., \& Rossi, M. (2019). Attitudes toward intimate partner violence against women in Latin America and the Caribbean. SAGE Open, 9(3). https://doi.org/10.1177/2158244019871061

Canada: Immigration and Refugee Board of Canada. (2012). Belize: Domestic violence, including state protection. https://www.refworld.org/docid/53ecbfe $34 . \mathrm{html}$ 
Crenshaw, K. (1989). Demarginalizing the intersection of race and sex: A Black feminist critique of antidiscrimination doctrine, feminist theory and antiracist politics. University of Chicago Legal Forum, 1989(1), 139-167.

https://chicagounbound.uchicago.edu/cgi/viewcontent.cgi?article=1052\&context=uclf

Crenshaw, K. (1991). Mapping the margins: Intersectionality, identity politics, and violence against women of color. Stanford Law Review, 43(6), 1241-1299. https://doi.org/10.2307/1229039

DeKeseredy, W. S., Dragiewicz, M., \& Rennison, C. M. (2012). Racial/ethnic variations in violence against women: Urban, suburban and rural differences. International Journal of Rural Criminology, 1(2), 184-202. https://doi.org/10.18061/1811/53699

DeKeseredy, W. S., \& Schwartz, M. D. (2008). Separation/divorce sexual assault in rural Ohio: Survivors' perceptions. Journal of Prevention \& Intervention in the Community, 36(1-2), 105-119. https://doi.org/10.1080/10852350802022365

Gentry, K. M. (2007). Belizean women and tourism work: Opportunity or impediment? Annals of Tourism Research, 34(2), 477-496. https://doi.org/10.1016/j.annals.2006.11.003

Hogg, R., \& Carrington, K. (2003). Violence, spatiality and other rurals. Australian \& New Zealand Journal of Criminology, 36(3), 293-319. https://doi.org/10.1375/acri.36.3.293

Lazarus, L. (2013). Working with marginalized and “hidden" populations: Researchers' anxieties and strategies for doing less harmful research. Caribbean Review of Gender Studies, 7, 122. https://pdfs.semanticscholar.org/be4e/7652051c1dc36a499252a2b6ef3e1ad37d67.pdf

Lewis, D. (2010). National gender-based violence plan of action. Women's Department Ministry of Human Development and Social Transformation Belize. http://scm.oas.org/pdfs/2012/CIM03206-A.pdf

Lykke, N. (2010). Feminist studies: A guide to intersectional theory, methodology and writing. Routledge. https://doi.org/10.4324/9780203852774

MacCormac, O. J., \& Romo, T. (2018). Challenges facing a woman wishing to report intimate partner violence in Belize. BMJ Case Reports, bcr-2018-226048. https://doi.org/10.1136/bcr-2018-226048

Maume, M. O., Lanier, C. L., Hossfeld, L. H., \& Wehmann, K. (2014). Social isolation and weapon use in intimate partner violence incidents in rural areas. International Journal of Rural Criminology, 2(2), 244-267. https://doi.org/10.18061/1811/61592 
Maydeu-Olivares, S. (2016). Violence: Central America's Achilles heel (T. Hardy, Trans.). Notes Internacionals, 142.

https://www.cidob.org/ca/publicacions/series_de_publicacio/notes_internacionals/n_142_ la_violencia_el_talon_de_aquiles_de_centroamerica/violence_central_america_s_achilles heel

McCall, L. (2005). The complexity of intersectionality. Signs: Journal of Women in Culture and Society, 30(3), 1771-1800. https://doi.org/10.1086/426800

McClaurin, I. (1996). Women of Belize: Gender and change in Central America. Rutgers University Press.

McClusky, L. J. (2001). “Here, our culture is hard”: Stories of domestic violence from a Mayan community in Belize. University of Texas Press.

Mignolo, W., \& Walsh, C. E. (2018). On decoloniality: Concepts, analytics, praxis. Duke University Press. https://doi.org/10.1215/9780822371779

Potter, H. (2013). Intersectional criminology: Interrogating identity and power in criminological research and theory. Critical Criminology, 21(3), 305-318. https://doi.org/10.1007/s10612-013-9203-6

Premdas, R. R. (2003). Belize: Identity and ethnicity in a multi-ethnic state. University of West Indies Working Paper. https:/www.open.uwi.edu/sites/default/files/bnccde/belize/conference/papers/premdas.ht $\mathrm{ml}$

Pruitt, L. R. (2008). Place matters: Domestic violence and rural difference. Wisconsin Journal of Law, Gender, \& Society, 23(2), 347-416. https://papers.ssrn.com/sol3/Delivery.cfm/SSRN_ID1323476_code366600.pdf?abstractid $=1276045 \&$ mirid $=1 \&$ type $=2$

Sagot, M. (2005). The critical path of women affected by family violence in Latin America. Violence Against Women, 11(10), 1292-1318. https://doi.org/10.1177/1077801205280189

Sandberg, L. (2013). Backward, dumb, and violent hillbillies? Rural geographies and intersectional studies on intimate partner violence. Affilia, 28(4), 350-365. https://doi.org/10.1177/0886109913504153

The Statistical Institute of Belize. (2013). Belize population and housing census 2010: Country report. http://sib.org.bz/publications/census-reports

Stewart, D. E., Aviles, R., Guedes, A., Riazantseva, E., \& MacMillan, H. (2015). Latin American and Caribbean countries' baseline clinical and policy guidelines for responding to intimate partner violence and sexual violence against women. BMC Public Health, 15(1). https://doi.org/10.1186/s12889-015-1994-9 
International Journal of Rural Criminology, Volume 5, Issue 2 (September), 2020

Tisdale, L. (2018). A triumphant victory for gay rights in Belize lays the foundation for a domino effect throughout the Caribbean. Loyola Los Angeles International and Comparative Law Review, 41(1), 99-123.

https://pdfs.semanticscholar.org/6736/a4eb62f5f2016aea7d632be4d9099f9afd07.pdf

Women's Commission. (n.d.). 2019: A glimpse into gender issues in Belize. Author.

World Health Organization. (2020). Frequently asked questions.

http://www.who.int/suggestions/faq/en/ 